\title{
Usage of perioperative anxiety neuromarker for improving the quality of life of a patient operated on for critical stenosis of the internal carotid artery
}

\author{
Mariusz Trystuła' ${ }^{\text {, Paweł Półrola }}{ }^{2}$, Juri Kropotov ${ }^{3}$ \\ ${ }^{1}$ Department of Vascular Surgery and Endovascular Interventions, John Paul II Hospital, Kraków, Poland \\ ${ }^{2}$ Faculty of Medicine and Health Sciences, Jan Kochanowski University, Kielce, Poland \\ ${ }^{3}$ Laboratory for Neurobiology of Action Programming, Institute of the Human Brain, Russian Academy of Sciences, \\ St. Petersburg, Russia
}

Trystuła M, Półrola P, Kropotov J. Usage of perioperative anxiety neuromarker for improving the quality of life of a patient operated on for critical stenosis of the internal carotid artery. Ann Agric Environ Med. 2016; 23(4): 612-617. doi: 10.5604/12321966.1226855

\begin{abstract}
I Abstract
Objective. The aim of the study was to find a neuromarker of perioperative anxiety in a patient with critical carotid stenosis through the use of neuromarkers in Quantitative EEG (QEEG) and Event Related Potentials (ERPs). The indirect purpose of the research was evaluation of improvement in the patient's quality of life.

Case study. A 45-year-old woman was admitted to the Department of Vascular Surgery and Endovascular Interventions at the John Paul II Hospital in Krakow, with the diagnosis of critical internal carotid stenosis (over $80 \%$ ), confirmed by Doppler Ultrasound and Angio-CT examinations. Before hospitalization, the patient had not presented any symptoms of brain ischemia. It was found that severe anxiety on the Hospital Anxiety and Depression Scale (HAD) was worse before the surgery. After the operation, a reduction anxiety in occurred as well as an improvement in the majority of the dimensions of health. Therefore, her quality of life improved.

Conclusions. Significant changes were observed on the Hospital Anxiety and Depression Scale (HAD). Modern neurotechnologies measures are necessary to capture all the changes in the symptoms of anxiety before and after the operation for a carotid stenosis. ERPs might be used to select patients with neuromarker of perioperative anxiety, and subsequently to serve in proper psychological care and minimalize the perioperative risk of complications.
\end{abstract}

I Key words

surgery, QEEG, ERPs, psychological care

\section{INTRODUCTION}

Surgical treatment, especially critical carotid stenosi srevascularization, is connected with an extremely big emotional burden for the patient. This is associated with the knowledge that one of the most serious complications of revascularization using open surgery (endarterectomy) or endovascular procedures (angioplasty and stenting), is a stroke with all it consequences, such as paresis, paralysis, aphasia, and even death $[1,2,3,4,5]$.

Extreme anxiety related to the above-mentioned complications might negatively affect physiological parameters, both before and during anesthesia. In addition, preoperative anxiety may interfere with the postoperative course, causing a greater number of complications; it may also increase the intensity of postoperative pain and prolong the time of hospitalization $[4,5]$.

The concerns and fears of patients undergoing diagnosis and treatment are divided into:

1. fears about the consequences of the disease and its treatment;

1. procedural fears that arise from fears connected with treatment techniques.

Address for correspondence: Mariusz Trystuła, Department of Vascular Surgery and Endovascular Interventions, The John Paul II Hospital, Prądnicka 80, 31-202 Kraków, Poland

E-mail:m.trystula@szpitaljp2.krakow.pl

Received: 18 March 2016; accepted: 06 April 2016
While the first kind of fear is often unavoidable, the second is usually connected with some neglect in clinical care, related to limited contact, and too little time devoted by the doctor and other staff to the patient, and/or a lack of empathy $[5,6]$.

The symptomatology of anxiety is rich and diversified $[7,8,9]$, and includes such symptoms originating from the following:

1) respiratory and chest system: rapid breathing, apnea, pressure or pain in the chest, sighing;

2) skin system: sweating, flushes, fainting, hot and cold waves, cold sweats, 'goose bumps';

3) digestive and excretory system: nausea, vomiting, loss of appetite, stomach pressure, diarrhea, constipation or need to defecate, sensation of a full bladder and urinary incontinence;

4) heart and vascular system: tachycardia, arrhythmia, feeling faint, increased or decreased blood pressure;

5) musculo-skeletal system: chills, trembling shaking tremors, teeth chattering, eye blinks, tremors of the eyelids, 'weak legs', tension headaches;

6) mouth, throat and speech: difficulty in swallowing, dry mouth, throat tightness and pressure, stuttering, logorrhea, aphonia;

7) other symptoms: middle of the night insomnia, waking up early, balance disorder, blurred vision, tinnitus, dizziness, numbness and tingling, pain, tension, concentration problems, difficulty in thinking, anhedonia. 
Experiencing anxiety determines the quality of life, and this in turn is connected with the state of health, and therefore the health related quality of life [5].The concept of Health Related Quality of Life (HRQOL) was first defined by Schipper [10, 11] and refers to mental and physical health broadly defined. Therefore, on the one hand, HRQOL might be connected with the disease itself, while on the other, with cognitive, emotional disturbances which arise in consequence of this disease. In the case of critical stenosis of the ICA, this is connected with the spectrum of symptoms, among which some may influence the quality of life [5], and some might even be a threat to life itself [12].

An improvement in the quality of life of patients with critical stenosis of the Internal Carotid Artery (ICA) is possible only as a result of surgical treatment (revascularization). Such a solution always carries the burden of alert reaction which leads to a growth in stress and anxiety. Patients who are stress resistant are able to cope with this situation, whereas those who are vulnerable to stress may easily reach the stage of exhaustion and are prone to an emotional 'roller coaster' [5]. When being taken to hospital these two groups will demonstrate a different level of perioperative anxiety, from mild, moderate to severe, or even panic. This can deteriorate, especially in those patients who do not have sufficient knowledge of the operation itself and its consequences. It is obvious that a patient who is aware of the operation procedures, ways of anesthesia, and the risks and consequences, is more capable of coping with their emotions when compared to those who do not possess an adequate knowledge, partial, or any knowledge at all [5].

It is worth mentioning that frequently those patients who are unaware seek this knowledge wherever they can. They ask other patients, who are not professionals and do not have a sound knowledge of the disease and the operation, or they try to find information via websites which, as we know, often include unverified, and even false information. In addition, the patient cannot choose the proper information from 'Dr. Google', mostly due to the lack of knowledge which, in consequence, may lead to even more intense anxiety. Google information seekers may either find information which will contribute to the achievement of some form of relaxation from anxiety, while others, who focus on the negative aspects, may even experience states of panic $[5,13]$.

Perioperative anxiety in patients operated on as a result of critical carotid stenosis has not yet been sufficiently evaluated, therefore, there are also no standard procedures in the diagnosis and treatment of such cases [5]. However, attempts are still being made to find some solutions to understand the mechanism of perioperative anxiety, and to explain the differences as to why some patients are able to find a strategy for coping, while others are unable to do so. New neurotechnologies, are a solution some extent as they may offer a way forward. The research is being conducted in three ways:

1) psychological procedures based on psychological care, including informative conversation and psychotherapy (if necessary);

2) proper education about the actions taken before, during, and after the operation;

3) good communication with the patient, especially with the medical staff, directed towards relaxing the patient and preventing the strengthening the anxiety [6].
Especially promising is the evaluation of Event Related Potentials which serve the possibility of designating a neuromarker of anxiety in the cases mentioned. Such a modern diagnostic path for perioperative anxiety is ergonomic (due to its costs, duration and effectiveness). For the presented study it was decided to use these neurotechnologies to test the study patient, who demonstrated a clinically broad spectrum of symptoms connected with severe anxiety, leading even to a state of panic.

\section{OBJECTIVE}

The aim of the study was to find a neuromarker of perioperative anxiety in a patient with critical carotid stenosis through the use of Quantitative EEG (QEEG) and Event-Related Potentials (ERPs). An indirect purpose of the research was evaluation of any improvement in the patient's quality of life.

\section{MATERIALS AND METHOD}

Ethics statement. According to the guidelines of the Helsinki Declaration (2008), subjects participating in the experiment were informed in detail about the test procedure, and provided written consent for participation in the project. The study protocols received ethical approval from the Ethical Committee of the Regional Medical Chamber (KB6/16).

\section{CASE REPORT}

A 45-year-old woman was admitted to the Department of Vascular Surgery and Endovascular Interventions at the John Paul II Hospital in Krakow, Poland, with the diagnosis of critical Internal Carotid Artery (ICA) stenosis (more than $80 \%$ ), confirmed by Doppler-ultrasound and AngioTomography. Before hospitalization, the patient was asymptomatic (without any incident of Transient Ischemic Attack or stroke). She was qualified for carotid revascularization as the primary prevention of an ischemic accident in the brain. The patient underwent eversion endarterectomy with protection of the brain using a drain shunt fixed during surgery to minimize the time of cerebral ischemia.The surgical operation was performed under general anesthesia at the special request of the patient. Illustrations of the successive stages of ICA endarterectomy are presented in Figure 1.

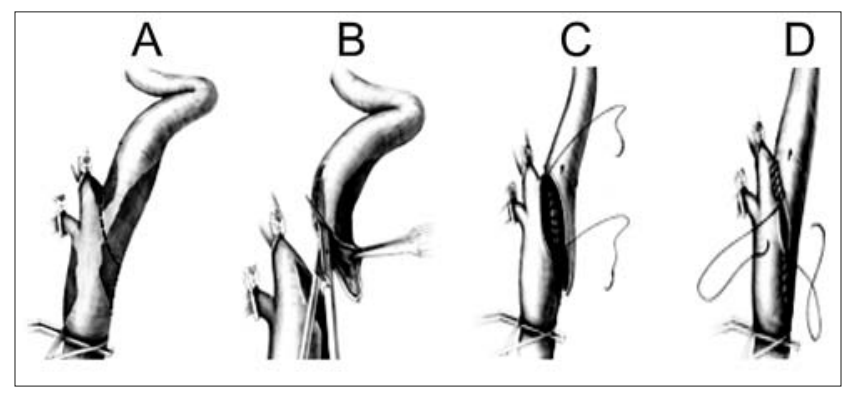

Source: Zarins et al. [14], with modification.

Figure 1. Illustrations of successive stages of ICA endarterectomy.

A - Selected cut-off line of the ICA.

$B$ - Endarterectomy of ICA and CCA.

$C$ - Attaching ICA to the CCA. B - Sewing process of ICA and CCA 
Subsequent stages of ICA endarterectomy are shown in Figure 2.

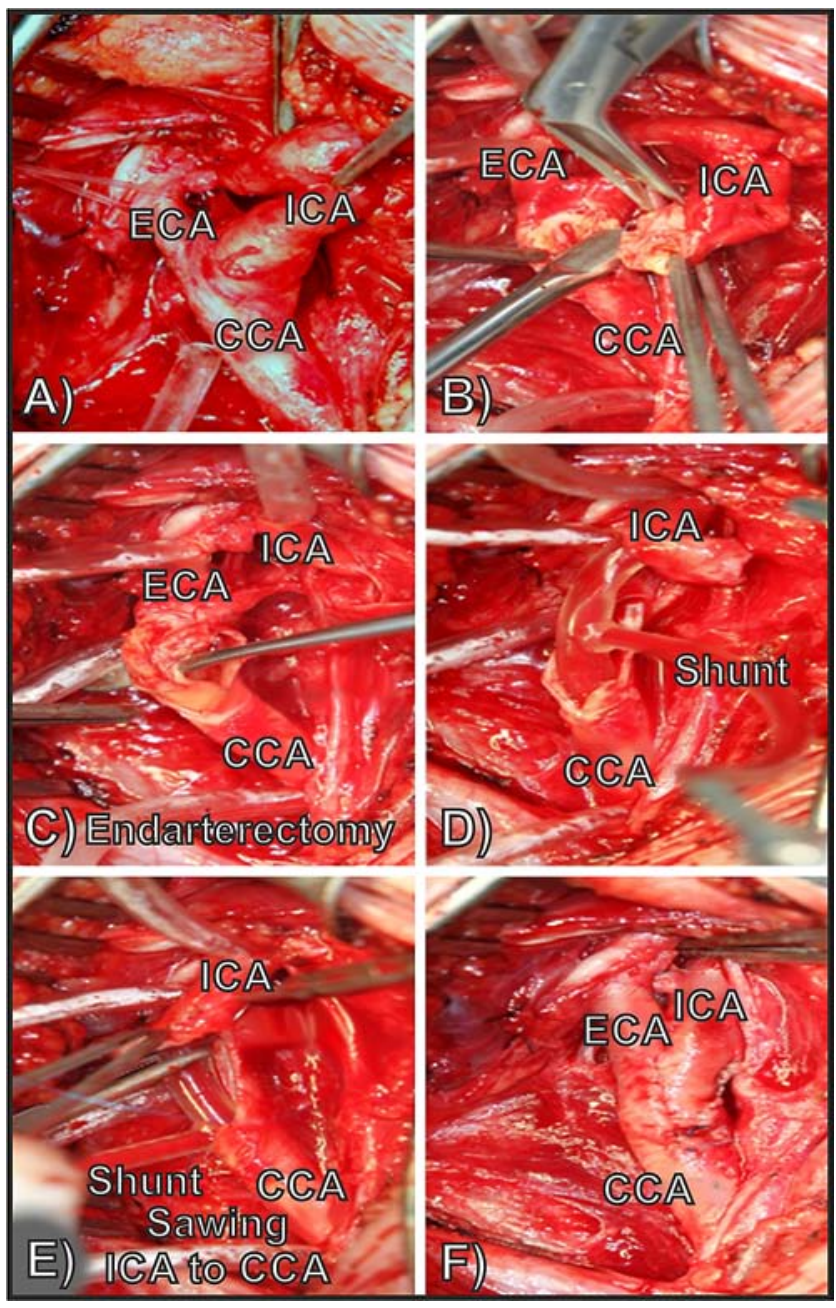

Figure 2. Subsequent stages of ICA endarterectomy.

A) Dissected CCA and ICA.

B) Removal of atherosclerotic plaque from ICA.

C) Removal of atherosclerotic plaque from the CCA and ECA after ICA cut-off.

D) Indwelling the shunt to the CCA and ICA

E) Sewing procedure of CCA and ICA.

F) View of reconstructed vessels. It should be stressed that the ICA is not angulated and straightened

On the side of the, a 7-centimeter- long skin incision was made through which the critically stenotic carotid artery was reached. After deadlocking the Common Carotid Artery (CCA), the Internal Carotid Artery (ICA) was cut off from the Common (CCA) and External Carotid Artery (ECA). A drain shunt was attached, and after making sure that the drain did not contain any air bubbles, blood clots, or plaque, the blood flow to the brain was restored. Plaque was removed by the eversive technique. ICA was sewn back into the CCA and ECA. Before completion of stitching, the shunt was removed. The procedure was carried out without any complications, and lasted 1 hour and 35 minutes, whereas the deadlock time lasted 2 minutes and 25 seconds before the fixing of the shunt, and 1minute and 20 seconds after its removal. After the surgery, the patient was hospitalized for three days. She was discharged home in a good general condition without cardiopulmonary and respiratory complications. The wound was healing by first intention and without any neurological deficits. In the first two days after the surgical operation, the patient experienced a fear of performing movements and had great difficulty in daily functioning.

The symptoms associated with anxiety taken from the structured interview and observation of the patient's behaviour are shown in Table 1.

Table 1. Symptoms of anxiety observed in the patient before and after the operation

\begin{tabular}{lll}
\hline $\begin{array}{l}\text { Origin of symptoms } \\
\text { of anxiety }\end{array}$ & One day before the operation & $\begin{array}{l}\text { Three days after } \\
\text { the operation }\end{array}$ \\
\hline $\begin{array}{l}\text { respiratory and } \\
\text { chest system: }\end{array}$ & pressure and pain in the chest, sighing & rapid breathing \\
\hline skin system: & $\begin{array}{l}\text { sweating, flushing, fainting, hot and } \\
\text { cold waves, cold sweats, 'goose bumps' }\end{array}$ & $\begin{array}{l}\text { cold sweats, } \\
\text { goose bumps' }\end{array}$ \\
\hline $\begin{array}{l}\text { digestive and } \\
\text { excretory system: }\end{array}$ & $\begin{array}{l}\text { nausea, vomiting, stomach pressure, } \\
\text { sensation of a full bladder and urinary } \\
\text { incontinence }\end{array}$ & $\begin{array}{l}\text { nausea, stomach } \\
\text { pressure }\end{array}$ \\
\hline $\begin{array}{l}\text { heart and vascular } \\
\text { system: }\end{array}$ & $\begin{array}{l}\text { tachycardia, arrhythmia, increased } \\
\text { blood pressure }\end{array}$ & None \\
\hline $\begin{array}{l}\text { musculo-skeletal } \\
\text { system: }\end{array}$ & $\begin{array}{l}\text { trembling shaking tremors, 'weak legs', } \\
\text { tension headaches }\end{array}$ & $\begin{array}{l}\text { chills, shaking, } \\
\text { teeth chattering }\end{array}$ \\
\hline $\begin{array}{l}\text { mouth, throat and } \\
\text { speech: }\end{array}$ & $\begin{array}{l}\text { difficulty in swallowing, dry mouth, } \\
\text { throat tightness and pressure }\end{array}$ & $\begin{array}{l}\text { difficulty in } \\
\text { swallowing, dry } \\
\text { mouth }\end{array}$ \\
\hline & $\begin{array}{l}\text { middle of the night insomnia, waking } \\
\text { up early, balance disorder, tinnitus, } \\
\text { dizziness, numbness and tingling, pain, } \\
\text { tension, concentration problems }\end{array}$ & $\begin{array}{l}\text { tinnitus, tension } \\
\text { other symptoms: }\end{array}$ \\
\hline
\end{tabular}

It is noteworthy that in the first examination (a day before the operation) these symptoms occurred in all the systems. After the operation, the anxiety diminished. It was found, however, that most of the symptoms had a lower intensity. The most striking fact was that the symptoms disappeared in the cardiovascular system totally. On the third day after the surgical operation, the patient began to function almost normally, but with the doctor's recommendation of a limitation in activities. Within ten days the pain in the wound slowly decreased.

The patient had a fear of 'not waking up' after the operation. She was also afraid of waking up during surgery. Situational anxiety was associated with the perioperative period, influenced by such factors as lack of previous experiences with anesthesia and surgery, and position in the schedule (beginning or end of the list). After the operation, the severity of anxiety was lower, even though she was afraid of the results of the operation, the pain, vomiting, or paralysis. She also displayed free floating anxiety.

Although the symptoms of perioperative anxiety were reduced, they still persisted, and the patient was offered ten sessions of neuro-feedback. The relaxation training protocol described in detail in another work was used [15].

The data obtained by the patient in The Hospital Anxiety and Depression Scale (HAD) in the first (one day before), second (three days after the operation) and third examination (one month follow up) are shown in Figure 3.

Before the operation the patient had severe anxiety (19 points). It was interesting that three days after the operation the anxiety was reduced, although it still persisted at a moderate level (15 points). One month later, after the neurofeedback, it had reduced to the normal level (4 points). Amazingly, a completely different trend was observed with depression. Before the operation, the patient had mild depression (6 


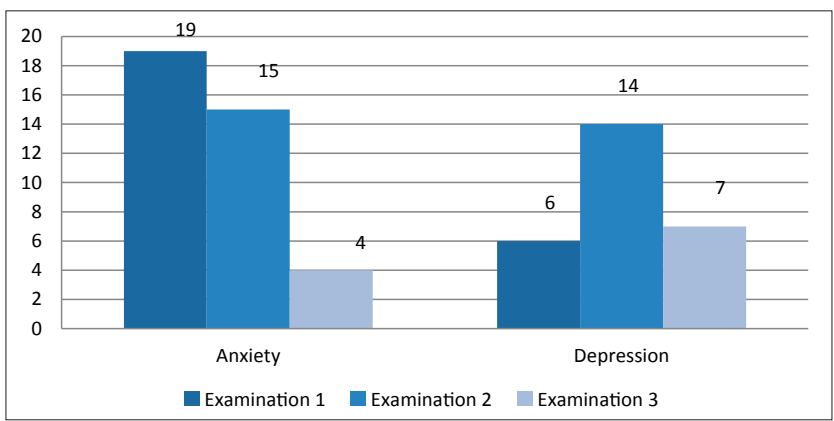

Figure 3. Data obtained by the patient in The Hospital Anxiety and Depression Scale (HAD) in the first (one day before), second (three days after the operation) and third examination (after one month)

points); then, surprisingly, three days after the operation, the depression increased and reached the low range of a moderate level (14 points). One month later, after the neurofeedback, it had reduced to the mild level (7 points).

The results presented above suggest that this patient has an anxious personality connected with emotional sensibility [5]. This finding was confirmed in neurophysiological testing with the use of the neuromarkers in Quantitative EEG (QEEG) and Event-Related Potentials (ERPs), and the discovery of a neuromarker of perioperative anxiety.

The Quality of Life Short Form - 36 Scale - was employed to evaluate the quality of life of the patient (Fig. 4).

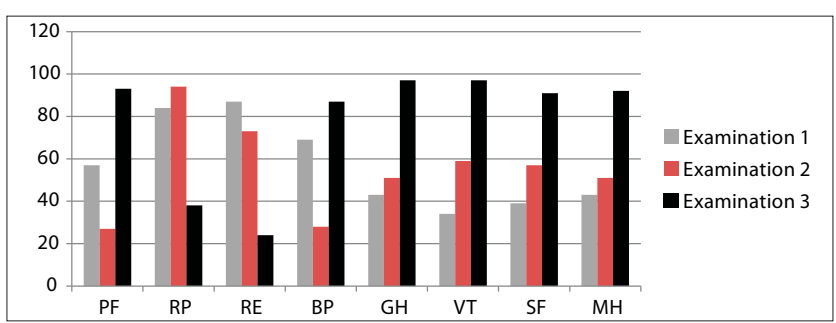

Figure 4. Data obtained by the patient in the SF-36 Scale in the first (one day before), second (three days after the operation) and third examination (after neurofeedback). PF - physical functioning; RP - role limitations due to physical health problems; RE - role limitations due to emotional problems; BP - bodily pain; GH - general health perceptions; VT - vitality; SF - social functioning; $M H$ - general mental health

It can be seen that prior to the operation a significantly decreased quality of life was observed in all the tested parameters. After the operation, the quality of life significantly improved, but the patient reported limitations in physical functioning, role limitations due to physical health problems, and emotional problems (especially anxiety), and bodily pain. She also had some complains about general health perceptions, vitality, and social functioning. She isolated herself socially, and also reported complaints about her general mental health.

On completion of the neurotherapy programme, the patient achieved a significant improvement in all the tested parameters studied, and her quality of life had improved.

Behavioural parameters. Table 2 shows the omission and commission errors, reaction time and reaction time variance for the first recording before treatment. No deviations from the reference are observed at the pre-treatment session.
Table 2. Behavioural data in the cued GO/NOGO task

\begin{tabular}{lcccc}
\hline & $\begin{array}{c}\text { Omission } \\
\text { errors }\end{array}$ & $\begin{array}{c}\text { Commission } \\
\text { errors }\end{array}$ & $\begin{array}{c}\text { Reaction } \\
\text { time (RT) } \\
\text { in ms }\end{array}$ & $\begin{array}{c}\text { Error of RT } \\
\text { Variance } \\
\text { in ms }\end{array}$ \\
\hline $1^{\text {st }}$ recording & $0 \%$ & $0 \%$ & 360 & 9.4 \\
\hline $2^{\text {nd }}$ recording & $3 \%$ & $0 \%$ & 387 & 11.9 \\
\hline Healthy controls & $3.4 . \%$ & $0.5 \%$ & 403 & 7.9 \\
\hline p-value for 1 rec & 0.70 & 0.56 & 0.66 & 0.64
\end{tabular}

EEG spectra. A clear frontal alpha asymmetry (>70\%) was found for alpha at F7-F8 electrodes. A peak in the alpha frequency band (around $9.5 \mathrm{~Hz}$ ) is observed at, but not at F8 (Fig. 2a). In addition, in the EEG spectra in all three conditions (EO, EC, GO/NOGO task), an excess of the parietal alpha rhythm (around $11.5 \mathrm{~Hz}$ ) was found at $\mathrm{Pz}$ (Fig. 5a).
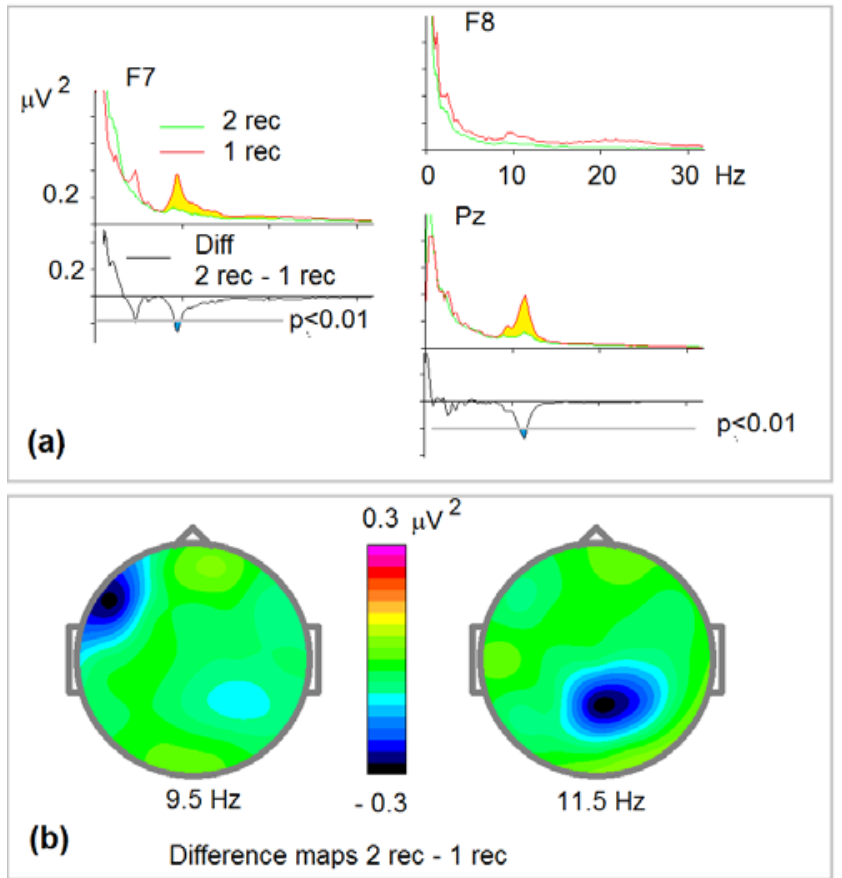

Figure 5. EEG spectra in the task condition for the 1st and 2nd recordings and their differences after neurofeedback sessions. a) EEG spectra for F7, F8 and Pz for the first recording - red; for the second recording - green; and the difference wave - 2 rec -1 rec. Note the significant $(p<0.01)$ decrease in the alpha frequency band. $b)$ the maps of the difference spectra at the alpha frequency band

Event Related Potentials (ERPs). Figure 3 shows ERP for the first recording (Pre) in response to the first presentation of the stimuliin the trial. Note the excessive amplitude of P1 wave in comparison to the reference. 

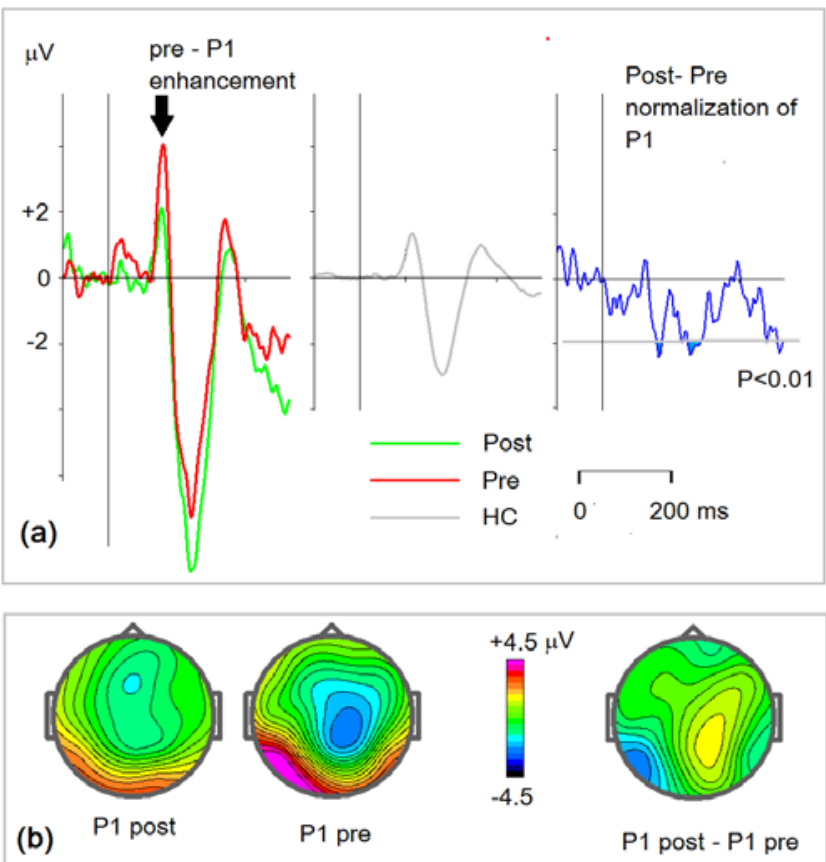

Figure 6. P1 as a neuromarker of anxiety.

a) from left to right: ERPs for the subject at T5 for the presentation of the animal at the first position in the trial: green - post, red - pre. The corresponding grand average ERP for the healthy control group (HC).The post- pre-difference wave. average ERP for the healthy
Confidence level $-p<0.01$.

b) maps at P1 latency $(120 \mathrm{~ms})$ for post-, pre- and the difference

\section{DISCUSSION}

Detection of the presence of the neuromarkers of anxiety in Quantitative EEG (QEEG) and Event Related Potentials (ERPs) in the patient before the surgical operation, made possible not only confirmation of the diagnosis of the presence of strong anxiety, but also allowed preparation of the patient for the operation [15] in accordance with the strategic approach specified by the individual needs of a patient with critical ICA stenosis [12]. At the same time, the main aim was to determine the methods of operation suitable for the patient, the kind of anesthesia to be used, together with the patient's full acceptance of the latter. Additional aims were connected with solutions for minimizing problems coexisting with the disease, its treatment and hospitalization. Therefore, the main goal was to carry out the surgical operation with the informed consent of the patient. This meant that patient had to decide which type of procedure of the two methods presented (endarterectomy vs. angioplasty), and anesthesia (local vs. general) should be performed [16].

Sub-goals were achieved through acquainting the patient with the most important procedures (depending on their intellectual capacity), such as: the necessity of blood sampling, catheterization of the bladder, obtaining permanent access to the vein or artery (venous or arterialline), changes of dressings, and connection to constant ECG and blood pressure monitoring. In other words, subgoals were met with regard to the patient's individual psychological problems connected with treatment and surgical operation.

One of the most important problems reported by all patients awaiting an operation is perioperative anxiety. This is strongly associated with the personality of the patient, and such patients who manifest a high anxiety level which might be displayed by multiple somatic symptoms. Those symptoms might subsequently interfere with the perioperative course, as in the presented case.

The modern neurotechnologies used in the current case to detect the neuromarker of anxiety, and to confirm both anxiety and the state of anxiety readiness in the patient as a presumed condition, helped to minimize this anxiety by the introduction of additional psychological procedures offered by the whole medical staff, according to the biopsychosocial model, in which special emphasis is placed on the co-operation of the treatment team (cf. also [17]). It can be argued that for this patient and for others with critical stenosis of the ICA, such cooperation will also be important before and after the operation. Disregarding this aspect may result in an increased incidence of complications after surgery [18]. This is connected with the fact that people may perform poorly under the influence of anxiety. This concerns the cognitive, as well as perceptual-motor performance [2].

The case study presented above includes conclusions of an applicable manner. Firstly, modern diagnostics of perioperative anxiety is necessary, and secondly, highly professional assistance in cases of particularly strong feelings of anxiety with a full spectrum of psychosomatic symptoms, is of great importance [5]. It is essential to capture the first symptoms of complications (e.g. bleeding from the surgical wound). This may prevent the patient from consecutive treatment or reduce the effects of complication $[19,20,21]$.

To allow for such care to be constant and systematic, the training of both staff and patients is necessary. Nurses and psychologists play a special role in such cases as they have the closest and most frequent contact with the patient. They are therefore the first in the front line.

The results of the presented case study might assist in the selection of patients with perioperative anxiety before the surgical operation, and who require special psychological care. The procedure demonstrated in this study can minimize operational risks and improve perioperative care. Special attention should be paid to those patients in whom are found the neuromarker of anxiety in Quantitative EEG (QEEG) and Event Related Potentials (ERPs). Such patients display worse perioperative stress-coping strategies, and they should be offered a proper neurotherapy protocol.

\section{CONCLUSIONS}

Modern neurotechnologies measures are needed to capture all changes in the symptoms of anxiety before and after an operation on the carotid stenosis. ERPs might be used to select patients with a neuromarker of perioperative anxiety, and subsequently, to provide proper psychological care and minimize the perioperative risk of complications.

\section{REFERENCES}

1. Hopkins R O, Key C W, Suchyta M R, Weaver L K, Orme J F. Risk factors for depression and anxiety in survivors of acute respiratory distress syndrome. Gen Hosp Psychiatry. 2010; 32(2): 147-155.

2. Nieuvenhuys A, Oudejans R R D. Anxiety and perceptual-motor performance: toward an integrated model of concepts, mechanisms, and processes. Psychol Res. 2012 Nov; 76(6): 747-759. 
3. Stroobant N, Vingerhoets G. Depression, anxiety, and neuropsychological performance in coronary artery bypass graft patients: a follow-up study. Psychosomatics. 2008; 49: 326-31.

4. Gasparis A P, Ricotta L, Cuadra S A, Char D J, Purtill W A, Van Bemmelen P S, et al. High-risk carotid endarterectomy: fact or fiction. J Vasc Surg. 2003; 37: 40-46.

5. Pąchalska M, Kaczmarek B L J, Kropotov J D. Neuropsychologia kliniczna: od teorii do praktyki. Warszawa: Wydawnictwo Naukowe PWN; 2014 (in Polish).

6. Klevit H D, Bates A C, Castanares T, Kirk E P, Sipes-Metzler P R, Wopat R. Prioritization of health care services: a progress report by the Oregon Health Services Commission. Arch Intern Med. 1991; 151: 912-6.

7. Ziębicka J, Gajdosz R. Wybrane aspekty lęku u chorych oczekujących na operację. Borgis - Anestezjol IntensywnaTerapia 2006; 1: 41-44.

8. Williams J M G, Watts F N, MacLeod C, Mathews A. Cognitive psychology and emotional disorders. Chichester 1997.

9. Bromboszcz A. Stres operacyjny. Spektrum 1980; 1: 23 (in Polish).

10. Shipper H. Quality of life: principles of the clinical paradigm. J Psychosoc Oncol. 1990; 8(23): 171-185.

11. Mangione C M, Goldman L, Orav E J, Marcantonio E R, Pedan A, Ludwig L E, Donaldson M C, Suqarbaker D J, Poss R, Lee T H. Health-Related Quality of Life After Elective Surgery. Measurement of Longitudinal Changes. J Gen Intern Med. 1997 Nov; 12(11): 686-697.

12. Trystuła M, Brzychczy A, Sułkowski L, Kazibudzki M, Misztal M, Musiałek P, Odrowąż-Pieniążek P. The quality of life of a patient with an iatrogenic brain stroke after angiosurgical treatment following the implant of a stentgraft into a dissected thoracic aorta with a congenital anatomical anomaly of branching of the right subclavian artery (arteria lusoria). Acta Neuropsychologica 2016; 14(1): 17-26.

13. Lloyd A J, Hayes P D, London N J M, Bell P R F, Naylor AR. Does Carotid Endarterectomy Lead to a Decline in Cognitive Function or Health Related Quality of Life? J Clin Exp Neuropsychol. 2004; 26(6): 817-825.

14. Zarins C K, Gewertz B L. Atlas chirurgii naczyń. Wydawnictwo: Urban \& Partner. 2007 (in Polish).

15. Kropotov J D. Quantitative EEG, Event Related Potentials and neurotherapy. San Diego: Academic Press, Elsevier; 2009.

16. Marrocco-Trischitta M M, Bandiera G, Camilli S, Stillo F, Cirielli C, Guerrini P. Remifentanil conscious sedation during regional anaesthesia for carotid endarterectomy: rationale and safety. Eur J Vasc Endovasc Surg. 2001; 22: 405-409.

17. Pąchalska M, Kaczmarek B L J, Kropotov J D. Neuropsychologia kliniczna: od teorii do praktyki. Warszawa: Wydawnictwo Naukowe PWN; 2014.

18. Ahn S S, Marcus D R, Moore W S. Post-carotid endarterectomy hypertension: association with elevated cranial norepinephrine. J Vasc Surg. 1989; 9: 351-360.

19. Brott T G, Hobson R W, Howard G, et al. Stenting versus endarterectomy for treatment of carotid-artery stenosis. N Engl J Med. 2010; 363: 11-23.

20. Van Mook W N, Rennenberg R J, Schurink G W, et al. Cerebral hyperperfusion syndrome. Lancet Neurol. 2005; 4(12): 877-888.

21. Yadav J S, Wholey M H, Kuntz R E, et al. Protected carotid-artery stenting versus endarterectomy in high-risk patients. N Engl J Med. 2004; 351(15): 1493-1501. 